臨床耳鼻：第3卷・第2號・ 1992

Clin. Otol. pp $348 \sim 352$

Vol. 3, No. 2, 1992

$$
\text { 외상성 외임파 누공 }
$$

원광대학교 의과대학 이비인후과학교실

장철호 · 이정헌

\title{
Traumatic Perilymph Fistula
}

\author{
Chul Ho Jang, M. D., Jung Hun Lee, M. D. \\ Department of Otolaryngology, Wonkwang University College of Medicine
}

$=$ Abstract $=$

Perilymphatic fistula(PLF) is one clinical manifestation of inner ear disease, in which fluid leaks from the inner ear to the middle ear cavity. Its symptoms are those of a cochlear lesion and/or vestibular lesion, depending on the affected region.

PLF occurs in a patient after various trauma-lifting, straining, coughing or other vigorous activities, barotrauma, stapedectomy and perilymphatic hypertension etc.

The diagnosis is easy when the injury result from an abrupt pressure change within the middle ear space, for instance, from changes in atmospheric pressure, scuba diving accidents, and slap injuries to the external auditory canal. However, PLF can also occur with much less severe trauma or may occur spontaneously, making the diagnosis much more difficult to estabilish. Unfortunately, there is no diagnostic test pathognomonic for PLF short of exploratory tympanotomy, and even this may not be totally reliable because some fistulas can leak intermittently.

Therefore, absolute criteria for exploration of the middle ear do not exist. Exploration of the middle ear is indicated in patients who have a progressive sensorineural loss or in whom the hearing loss is stable but vestibular symptoms continue despite conservative therapy. The authors experienced 3 cases of PLF associated with various trauma. The purpose of this paper is to represent 3 cases with the review of pertinent literaturs.

KEY WORDS: Traumatic perilymph fistula $\cdot$ Exploration.

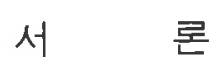

외임파누공은 내이에서 중이로 외임파액이 유출되는 연결을 가진 일종의 내이질환의 임 상증세를 나타낸다.

외임퐈누공은 원인에 따라 선천적인 경우와
외상에 의한 경우로 구분할 수있다. 외상성외 임파누공은 소아, 성인에서 나타날 수 있으며 대다수 소외임파누공을 가지고 있다. 주로 등 골적출술후(stapedectomy), 두부외상, 압력손 상(barotrauma) 등에 기인한다. 외임파누공의 빈도가 아직은 적은 편이나 최근 관심도는 증 
가하고 있드 저자돌은 최근엠 외상성외임파누 공을 추정진단하여 수술적 요법으로 치료한 3 례를 문헌고찰과 함께 보고하는 바이다.

\section{증 례}

\section{증례 1 :}

56세된 남자로 하악골 osteoradionecrosis로 91년 4월 부분하악골절제술 및 metal mesh 이 식술을 시행하였으며 수술후 감염을 예방 치 료하기 위하여 고압산소치료기에 넣어 치료를 하였다. 한 주기당 일주일에 5 일, 하루에 45 분 2 기압하 $100 \% \quad 02$ 에서 2 주기를 시행하였다. 주기사이에 2 일 휴지기(rest)를 두었으며 흥부 $\mathrm{X}$-ray와 폐기능 검사를 시행하였다(그림 1).

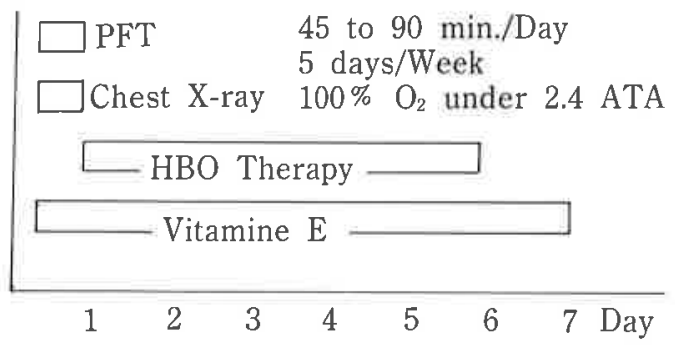

Fig. 1 Protocol for HBO Therapy

환자는 2 주기 시행 5 일째 좌측이에 이충만감, "쏴아"하는 이명, 중등도의 현훈을 동반한 양 측 돌발성 난청을 호소하였다. 이학적검사상 우측은 경도의 전음성 난청 (기도 $35 \mathrm{~dB}$ ) 좌측은 골도 청력이 $65 \mathrm{~dB}$ 이하였다. 1 주일간 보존적 치료후에도 돌발성 난청이 반응을 보이지 않아 압력에 의한 외임파누공을 의심하고 좌측이 시험적 중이개방술을 시행하였다. 난원창에서 누공을 관찰할 수 있었으며 동측의 내경정맥을 압박시 더 많은 양의 외임파액의 유출을 확인 할 수 있었다. Bosmin을 묻힌 솜을 누공부위에 압박하고 난원창 주변의 점막을 pick으로 벗긴 후 fibrin glue를 사용하여 이개연조직이식을 시행하였다. 이때 난원창 주변의 점막을 pick 으로 벗긴 이유는 이개연조직이식의 확실한
고정을 위해서였다. 수술후 이명은 점차 회복 되었으며 재발되지 않았으나 좌측 골도 청력은 $5 \mathrm{~dB}$ 의 개선외에는 뚜렷한 청각 개선은 나타나 지 않았으며 이는 2 주기 동안에 걸친 지속적인 고압으로 인한 내이 손상으로 추정되었다.

\section{증례 2 :}

46세된 남자로써 내원 2일전 야유회에서 만 취된 상태로 꽹과리를 귀에 대고 놀다가 강한 소음에 3 시간 정도 노출되어, 우측귀에 "칙"하 는 이명과 현훈을 동반한 돌발성 난청이 발생 하여 91 년 8월 내원하였다.

이핮적 검사상 양측 고막은 정상이었으며 순음청력검사상 좌측은 정상 우측은 골도 55 $\mathrm{dB}$ 의 감음성난청을 보였다. 2 주일간 돌발성 난청의 보존적 치료를 시행하였으나 호전이없 고 자가강청이 소실되지 않아 외임파누공을 의심하고 시험적 중이 개방술을 시행하였다. 난원창 niche 주변에 외임파액이 고인것을 확 인하였으며 Hough curette으로 niche를 조금제 거한 뒤 이소골에 압력을 가할 시 난원창 하 부에서 누출됨을 확인할 수 있었다.

Gelfoam에 bosmin을 soaking하여 난원 창하 부에 압럭을 가하고 난원창 주변점막을 whirly bird로 약간 벗겨내 이개연골막을 채취하여 fibrin glue와 함께 이식하였다. 수술후 2 주일째 우측 골도는 중저음역에서 $35 \mathrm{~dB}$ 로 호전되었으 며 한달후 $30 \mathrm{~dB}$ 로 호전되었다. 환자는 재발되 지 않고 현재까지 양호한 경과를 보이고 있다.

\section{증례 3 :}

57 세된 여자로써 좌측 귀에 8 주간의 청력감 퇴, 이충만감, 현훈 등을 주소로 91 년 10 월 내 원하였다. 과거력상 환자는 우측귀는 농이었으 며 좌측귀는 정상청력이었다. 91년 8월 타병원 에서 척추추간판증으로 척추 마취하에서 수술 을 받았으며 마취가 회복된 상태에서 소변을 보다가 방광은 팽만되어 배설욕구는 있어도 소변이 전혀 나오지 않아 $5 \sim 10$ 분간 심한 복 압의 증가와 함께 배뇨를 하다가 좌측 귀에서 “팍”하는 소리를 느끼면서 돌발성 난청이 발 생하였다. 그후 개인병원에서 삼출성 중이염으 
로 오진받고 약물치료와 Valsalva, Politzerization을 시행하였으나 증상 호전이 되지 않고 오히려 현훈이 악화되어 본원으로 내원하였다. 내원 당시 우측 귀의 고막은 정상이었으며 좌 측은 고막의 후하부에 환기 튜브가 삽입되있 었으며 장액성이류가 있었다. 순음청력검사상 우측은 기도골도 $70 \mathrm{~dB}$ 의 농이었으며 좌측은 골도 $35 \mathrm{~dB}$ 의 감음신경성난청을 보였다. Fistula test상 좌측을 향한 안진이 의심되었다. 2 주일동안 Acopex 2.0mg IV, 1주일동안 Sagacin $60 \mathrm{mg} \mathrm{IM}$ 을 시행하고 dry 되어 수술 현미경하 에서 환기 튜브를 빼고 고막 변연부를 trimming한후 후방으로 myringotomy knife를 사용 하여 절개를 가하였다. 이소골 주변과 전원창, 난원창 주변을 조심스럽게 확인하였으나 유출 부위는 확인되지 않아 복압을 증가시켰더니 정원창 주변에 소량의 투명한 외임파액이 유 출되는 것을 확인할 수 있었다. 환자는 병변 발생부위가 only hearing이어서 수술을 주저하 여 surgicel 일부와 gelfoam으로 정원 창부위와 중이강을 채우고 packing을 하였다. 환자는 그 후 1 개월후 정상고막을 보였으며 청각은 골도 $20 \mathrm{~dB}$ 로 호전되었다.

\section{고 찰}

외임파누공은 1971년 Goodhill이 ${ }^{12,13)}$ 청원창 또는 난원창의 파열이 돌발적 난청을 일으킨 다는 보고후 중이 내압 또는 뇌척수압의 증가 후에 발생한 돌발성 난청 환자에게 원인으로써 외임파누공을 추정하게 되었으며 최근 이에 대한 연구가 활발히 진행되고 있다 11,13,24).

외임파누공은 원인에 따라 선천성과 외상성 으로 나눌 수 있다. 선천성외임파누공은 대개 유소아에서 볼 수 있으며 큰 누공을 가지고 있다. 대표적인 원인으로는 국내에서도 보고된 바 있는 Mondini dysplasia가 있으며 ${ }^{1,2)}$ 그외에 도 내이도 fundus결손, Hyrtl's fissure존재 등 과 같은 골부의 기형이 대다수를 차지한다.

외상에 의한 것은 연령에 관계없이 나타날 수 있으며 작은 누공을 가지고 있다. 원인으로
는 등골수술같은 이과수술, 압력손상(barotrauma), 두부손상, 진력 (physical exertion) 등 이 있다 ${ }^{3,9,10)}$. 저자들이 경헙한 증례는 압력손상 과 진력,음향손상(acoustic trauma)에 의한 것 이었다.

외임파누공의 발생기전은 2가지 즉 explosive mechanism과 implosive mechanism이 있 다 ${ }^{31}$. Explosive mechanism이란 뇌쳐수압의 상 승에 의한것으로 Nomura ${ }^{17,18,23,24)}$ 등의 실험적 연구에 의하면 guinea pig 31마리의 거미막하 공간 (subarachnoid space)에 인공외임파액 1 $2 m \ell$ 를 수초간 주입시 $90 \%$ 이상에서 양쪽 정원 창에 누공이 발생함을 관찰하였으며 와우의 미세변화를 관찰시 Reissner막의 팽대 혹은 파 열과 유모세포의 소실, Corti기관의 압박상태 를 보고하였으며 이로 인한 감각신경성 난청을 설명하였다. Implosive mechanism은 두부외상 이나 압력손상 둥에서 보이는 중이강내압력 상승에 의한다. 저자들의 증례 1,2 는 implosive mechanism, 증례 3은 explosive mechanism으 로 선명될 수 있다.

증례 3 에서와 같이 복합상승은 뇌척수압의 증가와 외림프압의 증가로 설명할 수 있으며 Calborg 등에 의해 실험적으로 증명된 바 있닿, 7.20).

외임파누공의 증상은 다양하며 전정기관과 와우기관의 누공의 크기에 따라 달라 질 수 있다. 외상성외임파누공은 청각 및 전정기 증 상을 주로 나타낸다. 청각증상으로는 돌발성이 며 고도의 감각신경성난청을 나타낸다. 주로 심한 이명과 충만감 둥이 동반된다.

외상성외임파누공의 진단에는 시험적 고실 개방외에는 확진이 없다. 따라서 상기 증상에 대한 자세한 병력문진이 큰 도움이 되며 이학 적 검사, 전정기능 검사, 청력 검사, 누공검사, tympanometric fistula test, ENG fistula test, electrocochleography, 측두골 $\mathrm{CT}$ 등이 필요하 당.

감별진단해야 할 질환으로는 다른 원인의 돌발성난청, Meniere병등이 있으며 특히 조심 해야될 중요한 것은 삼출성 중이염으로 오인 하고 Valsalva와 같은 중이 inflation을 시킬 때 
implosive mechanism에 의해 외임파누공은 더 악화될 수 있다 ${ }^{16.17)}$.

또한 촉두골 골절이 원인일때는 뇌척수액이 루를 감별하여야 한다 ${ }^{14,20)}$. 이를 위해서는 당검 사, halo test, metrizamide CT test 등을 시행 하여 구별할 수 있다.

외임파누공의 치료는 의심하는 즉시 중이를 개방하여 확인을 해야한다는 주장과 자연치유 를 위하여 $10 \sim 14$ 일 동안 보존적 치료를 주장 하는 상반된 의견이 있으나 좀더 적극적인 진 단과 치료가 필요하다. 특히 난청이 점점 심해 지는 경우, 어음분별력이 떨어지는 경우, 지속 적인 정위성 현훈이 있는 경우, 병력진단상 난 청이 발생할 때 막파열이 의심되는 “pop sound”가 들린 경우 Goodhill, Mattox 등은 22) 수술적 치로가 필요하다고 지적하였다. 수술시 누공을 확인하기 위해서는 5 10분동안 외임 파액이 흐르기를 기다리며 또는 Valsalva법, Trendelenburg체위를 취하거나, 경정맥을 압 박하거나 이소골연쇄의 조작 등이 일반적으로 인정되어 왔다. 그러나 이러한 조치들은 수술 후 난청을 더욱 악화시킬 수도 있다. 특히, 술 전 경도, 중등도 감각신경성난청일 경우 주의 하여야 한다고 지적한 보고도 있다.

외임파누공 호발 부위는 대개 정원창과 난 원창에 발생하나 보고자들에 따라 다양하다 4.15 , 16.19,29,30).

누공을 봉쇄하는 재료는 사용자에 따라 지 방조직, 연조직, 근막, 근육, gelfoam, bone clip, bone dust, 연골, 연골막, 골막 등이 보고되어 있다 ${ }^{22)}$.

저자들은 이개연골막을 fibrin glue와 함께 사용하였다21). 누공이 발견되지 않는 경우에도 누공이 의심되면 정원창과 난원 창을 덮어주는 것이 좋다고 한다. 또한 수술시에 외임파액과 마취액, 혈장 등과 구별이 안되는 경우도 있으 므로 누공 의심시 예방적으로 덮어주어야 한 다. 수술후 예후는 판단하기 힘드는데, 그 이 유로는 환자의 다양한 증상 환자의 나이, 전신 조건, 직업, 발생시기와 진단시기의 시간차이 등에 의한다. 수술후 청력개선의 결과는 보고 자에 따라 16 65\%로 다양하다. 현훈 개선은 $65 \sim 99 \%$ 정도이다 ${ }^{27.28)}$.
$8 \sim 17 \%$ 에서 수술후 재발이 보고되어 있는 데 25,26), 이러한 재발을 줄이기 위해 Argon LA$\mathrm{SER}$ 를 사용하여 정원창, 난원창 주변의 점막 을 vaporization시켜 fibrin glue를 사용하여 보 다 더 단단히 고정을 시킴으로써 좋은 결과를 얻을 수도 있다.

\section{요 약}

외상성외임파누공은 돌발성 난청의 병력 조 사와 증상에 따른 의심과 적극적인 시험적고실 개발술로 확진될 수 있다.

최근 저자들은 외상성외입파누공 3 례를 결 험하였으며 2 례에서 연골막과 fibrin glue를 사 용하여 좋은 치료결과를 얻었기에 보고하는 바이다.

\section{References}

1) 장선오 - 정필상 - 김종선 : 재발 성뇌막염 을 수반한 외임파누공. 한이인지 31(2): $336 \sim 340,1968$

2) 김종훈 - 김중강 - 이태휘 둥 : Monidini Dysplasia와 재발성 뇌막염. 한이인지 35 (4) : 493 499, 1992

3) Althaus SR:Perilymph fistulas. Laryngoscope $91: 538 \sim 562,1981$

4) Althaus SR, House HP: Long term results of perilymph fistula repair. Laryngoscope $83: 1502 \sim 1509,1973$

5) Black FO, Lilly DJ, Nashner LM et al: Quantitative diagnostic test for perilymph fistulas. Otolaryngol Head Neck Surg 96:125 134, 1987

6) Carlborg $\mathrm{B}:$ On physiological and experimental variation of the perilymphatic pressure in the cat. Acta Otolaryngol 91 : 19 28, 1981

7) Carlborg B, Densert O, Stagg J : Perilymphatic pressure in the cat. Description of a new method for study of inner ear 
hydrodynamics. Acta Otolaryngol 90 : 209 218, 1980

8) Causse JR, Causse JB, Bel J : Tympanometry and fistula test. Audiology 22: 451 462, 1983

9) Emmett JR, Shea JJ : Traumatic perilymph fistula Laryngogcope $90: 1513 \sim 15$ 20,1980

10) Fee GA: Traumatic perilymph fistula. Arch Otolaryngol Head Neck Surg 88: 43 46, 1968

11) Fisch U: Management of sudden deafness. Otolaryngol Head Neck Surg 95 : 344 346, 1986

12) Goodhill V : Sudden deafness and round window rupture. Laryngoscope $81: 14$ 62 1474, 1971

13) Goodhill V: Sudden deafness and labyrinthine window ruptures. Ann Otol Rhinol Laryngol $82: 2 \sim 11,1973$

14) Gundersen $T$, Haye $R$ : Cerebrospinal otorrhea. Arch Otolaryngol $91: 19 \sim 23$, 1970

15) Halerey A, Sade J : The perilymph fistula. Am J Otol $5: 109 \sim 112,1983$

16) House J W, Rizer F M : Perilymph fistulas in children. Am J Otol $89: 493 \sim$ 495, 1988

17) Hara M, Nomura $Y$, Saito $K$ : Histopathologic study of the perilymph-suctioned labyrinth. Ann Otol Rhinol Laryngol $99: 315 \sim 320,1990$

18) Kishimoto $S$, Nagahara $K$, Fisch $U$ : Inner ear pressure measurements : Effects of obstruction of the cochlear aqueduct and endolymphatic duct on the perilymphatic pressure. Otolaryngol Clin North America $16: 21 \sim 35,1983$

19) Luntz M, Frank I, Yurovitzki, et al: Large Perilymph fistulas. Am J Otol 7(4) :282 286, 1986

20) Moscovitch DH, Gannon RP, Laszlo CA
: Perilymph displacement by cerebrospinal fluid in the cochlea. Ann Otol Rhinol Laryngol 82: 53 61, 1973

21) Moretz WH, Shea JJ, Emmett JR, et al : A simple autologous fibrinogen glue for otologic surgery. Otolaryngol Head Neck Surg 95：122 124, 1986

22) Mattox De: Perilymph fistula. Otolaryngology Head \& Neck Surgery(ed Cummings $\mathrm{CW}$ et al), 1st ed. St Louis Mosby pp3113 3118, 1986

23) Nomura $Y$, Hara $M$ : Experimental perilymphatic fistula. Am J Otolaryngol 7: 267 275, 1986

24) Nomura Y : Otologic significance of the round window. Adv Otorhinolaryngol 33 : 1 162, 1984

25) Parell GJ, Becker GD : Results of surgical repair of inapparent perilymph fistulas. Otolaryngol Head Neck Surg 91 : $3 \sim 8,1983$

26) Ptter $\mathrm{CR}$, Conner GH: Hydrops following perilymph fistula repair. Larygoscope $93: 810 \sim 812,1983$

27) Rizer, House : Perilymph fistulas: The House Ear Clinic Experience. Otolaryngol Head Neck Surg 104(2) : 239 243, 1991

28) Robert I Kohut : Perilymphatic fistula : More than a century of notions, conjectures and critical studies. Am J Otol 13 : 38 40, 1992

29) Supance J, Bluestone $C$ : Perilymphatic fistulas in infants and children. Otolaryngol Head Neck Surg $91: 663 \sim 671,19$ 83

30) Seltzer S, McCabe B : Perilymph fistula : The Iowa experience. Laryngoscope 94 : 37 49, 1986

31) Simmons FB: Theory of membrane breaks in sudden hearing loss. Arch Otolaryngol $88: 67 \sim 74,1968$ 